\title{
Regional Distribution of Agricultural Incomes in Pakistan: An Intertemporal Analysis
}

\author{
M. GHAFFAR ChAUDhRY and ZAFAR IQBAL*
}

\section{INTRODUCTION}

The stagnant agriculture sector of the Fifties was transformed into a dynamic one in Pakistan by the technological breakthroughs made in the early Sixties. The installation of private tubewells, introduction of high-yielding varieties (HYVs) for various crops, the rising use of chemical fertilizers and insecticides and the mechanization of tillage operations have ensured growth rates of agricultural output unknown in the Indo-Pakistan subcontinent. Although the desirability of these technological changes in terms of growth cannot be doubted, it was argued in many studies that the technology would likely lead to increasing rural income disparities in Pakistan thus thwarting the desired impact of growth on economic development [Alavi (1976); Falcon (1970); Gotsch (1976); Gotsch (1976a); Griffin (1974); and Hamid (1974)].

The conclusion that rural income distribution worsens is attributed in part to interclass disparities but to a large extent to growing income differences among the various regions [Alavi (1976); Falcon (1970); Gotsch (1973); and Griffin (1974)] . In making the case for growing regional income disparities, these studies held the view that the benefits of the technology, would remain restricted to irrigated areas alone. Barani areas, with their dependence on natural precipitation alone, would be severely constrained in the adoption of high-yielding varieties (HYVs) and the application of chemical fertilizers (Falcon 1970). These apprehensions led to the conclusion of rising interprovincial disparities; Punjab with an elaborate system of canals and private tubewells is likely to make tremendous gains in agricultural production relative to other provinces especially Balochistan and NWFP where agricultural production has shown no visible signs of improvement [Alavi (1976); Falcon (1970); and Griffin (1974)]

The purpose of the present paper is to study the pattern and trends of regional distribution of agricultural incomes in Pakistan if only to check the appropriateness or inappropriateness of the technological breakthroughs on a regional scale. This is of crucial significance as low agricultural productivity cannot be raised without

*The authors are Chief of Research and Staff Economist respectively, at the Pakistan Ins̀titute of Development Economics, Islamabad. 
increasing dependence on modern agricultural inputs on a Pakistan-wide basis. The paper is divided into four sections dealing with data sources and methodology, intertemporal state of regional disparities and conclusions and policy recommendations.

\section{DATA SOURCES AND METHODOLOGY}

An empirical investigation of the trend of regional income distribution in agriculture requires consistent time-series data on value added by agriculture in various regions. As there is a general lack of consistent time-series data on national accounts disaggregated by regions, one must look for the alternative sources of data of regional incomes. ${ }^{1}$ Among the most viable of these sources is the valuation of crop-production data by districts. This adds tremendously to data requirements and calculation work. Not only does it requires timeseries data on production estimates of each and every agricultural commodity by districts but also relevant price statistics to arrive at gross value of agricultural output at the district level. Although highly laborious, we had no option but to undertake the task of preparing estimates of gross value of agricultural output for each district since 1960-61 to 1982-83. As a first measure of regional disparity, we aggregate the district data into shares of provinces in gross value of agricultural output.

In order to proceed further, the gross value of output of each district was divided by its respective population in agriculture to arrive at per capita incomes. Although agricultural population estimates for districts are not available other than population census years, they were interpolated on the basis of inter-censal growth rates of agricultural population in various districts. The calculation of per capita incomes was essential to arrange districts from lowest to highest per capita income and to calculate their income shares. The Gini coefficients reported in this paper, have been based on cumulative shares of population and of incomes of the various districts ordered by the lowest and highest per capita income.

\section{THE STATE AND TREND OF REGIONAL DISPARITIES}

As should be evident from the methodology, the analysis of regional income distribution may be based on income shares of various regions or income concentration ratios. We intend to use both in our paper.

\section{Regional Income Shares}

Taking income shares first, the Table 1 presents five-year averages of income

'Gross Provincial products are available for only a limited period of the Sixties (Naved 1974). However, the publication of such data was discontinued beyond the Sixties due perhaps to the inaccuracies involved. shares of various provinces of Pakistan beginning with the early Sixties. The data of this table point to the Punjab's dominant position in agricultural production as it accounted for a large proportion of 60-65 percent of Pakistan's agricultural output for the time period under consideration. This is understandable as Punjab accounts for nearly two-thirds of Pakistan's total cropped land. The important thing to note, however, is the significant fall in the Punjab's share of gross value of agricultural output between 1960 and 1980 irrespective of the prices used in the valuation of agricultural output. The decline in the Punjab's share was accompanied by the corresponding and almost uniformly distributed increases in the income shares of other provinces. It may not be without interest to reiterate two major implications of the rising share of other provinces in agricultural output. First, contrary to the generally held view, the increases in agricultural production were not confined to Punjab alone. They were widely and equally shared by other provinces. In fact, the rising production shares of other provinces are an indication of more rapid growth of agricultural production in the provinces of Sindh, NWFP and Balochistan than that in the Punjab in the post-Green Revolution period. Second, assuming Punjab is agriculturally the richest province, the rise in the share of agricultural production of other provinces implies a reduction in the regional disparity of agricultural incomes.

Table 1

Provincial Shares in Gross Value of Agricultural Output of Pakistan at Current Prices and 1959-60 Constant Prices

\begin{tabular}{lllll}
\hline \multirow{2}{*}{ Period } & \multicolumn{3}{c}{$\begin{array}{c}\text { Percentage Shares in Gross Value of } \\
\text { the Province of }\end{array}$} \\
\cline { 2 - 5 } & Punjab & Sindh & NWFP & Balochistan \\
\hline A. At Current Prices & & & & \\
1960-61 to $1964-65$ & 64.7 & 24.1 & 8.8 & 2.5 \\
1965-66 to $1969-70$ & 63.0 & 25.4 & 9.0 & 2.6 \\
1970-71 to $1974-75$ & 64.3 & 24.2 & 9.0 & 2.5 \\
1975-76 to $1979-80$ & 60.9 & 25.7 & 9.9 & 3.5 \\
1980-81 to $1982-83$ & 59.3 & 25.6 & 9.7 & 5.4 \\
B. At 1959-60 Constant Prices & & & & \\
1960-61 to $1964-65$ & 63.7 & 24.3 & 9.4 & 2.6 \\
1965-66 to $1969-70$ & 60.2 & 26.5 & 10.2 & 3.1 \\
1970-71 to $1974-75$ & 61.2 & 25.9 & 9.6 & 3.4 \\
1975-76 to $1979-80$ & 60.2 & 26.5 & 9.6 & 3.6 \\
1980-81 to $1982-83$ & 60.2 & 25.8 & 9.4 & 4.6 \\
\hline
\end{tabular}

Source: Calculations based on crop-production data in the Files of Planning Unit, Ministry of Food, Agriculture and Cooperatives. 
The income shares approach to income distribution, while useful in certain respects, suffers from many limitations. First, it assumes the constancy of the growth of agricultural population in various regions and variations in population growth may seriously affect the conclusions reached above. Second, it does not explicitly incorporate the levels of per capita income in the various regions. Third, income shares are only a rough means of pointing to the magnitude and trends of income distribution and cannot be used to measure the precise degree of income inequality and its trend. Finally, provincial aggregates of income shares hide more than they reveal for they fail to reflect on the intra-regional variations of income.

\section{Income Concentration Ratios}

The income concentration ratios are a useful device to overcome the limitations of the income shares approach in measuring income inequalities. Apart from being a precise measure of inequality, ${ }^{2}$ income concentration ratios also allow for incorporation of variations in population growth and per capita incomes in different regions. In addition, they can be profitably used to reflect on intraprovincial variation in income if based on district level data. It, therefore, seems advisable to supplement the conclusions of income shares approach by an analysis of income concentration ratios. Table 2 gives the relevant information in this regard.

The concentration ratios given in the above table point to the improvement of regional distribution of incomes between 1960-61 and 1982-83 irrespective of the use of current or 1959-60 prices on Pakistan-wide basis. The fall in concentration of income was most significant in the NWFP followed by Sindh and the Punjab. Although the regional distribution of income in Balochistan became less skewed between 1960-61 and 1979-80, it deteriorated since 1979-80 both at current prices and 1959-60 constant prices. The fall in the concentration ratio over the period under consideration in Pakistan. Punjab and Sindh (also in Balochistan) is considerably dampened by use of 1959-60 constant prices as compared to that of current prices. This implies that the price policy in Pakistan, Punjab, Sindh and Balochistan has been more favourable to relatively poorer regions than to well-to-do regions. In the case of NWFP, however, the reverse seems to be the case.

Looking at Table 2 one may jump to the conclusion that changes in concentration ratios are at best imperceptible and the decline in them over a long period of more than 20 years may not be given any value at all. Our statistical tests prove to the contrary. In separate regressions for each of the regions at constant and variable prices, the trend variable turned out to be statistically significant at the 5 percent significance level and only in one case, out of ten regressions, was the sign of the trend variable positive.

${ }^{2}$ The generalization holds true except in the case of intersecting Lorenz Curves leading to mbiguity of conclusions based on income concentration ratios.
Table 2

Income Concentration Ratios Based on District Data on Gross

Value of Agricultural Output per Capita since 1960-61

\begin{tabular}{|c|c|c|c|c|c|c|}
\hline & \multirow{2}{*}{ Period } & \multicolumn{5}{|c|}{ Income Concentration Ratios for } \\
\hline & & Pakistan & Punjab & Sindh & NWFP & Balochistar \\
\hline \multicolumn{7}{|c|}{ A. Current Prices } \\
\hline & $1960-61$ to $1964-65$ & 0.23 & 0.16 & 0.15 & 0.49 & 0.26 \\
\hline & $1965-66$ to $1969-70$ & 0.22 & 0.16 & 0.14 & 0.49 & 0.21 \\
\hline & $1970-71$ to $1974-75$ & 0.21 & 0.17 & 0.08 & 0.34 & 0.18 \\
\hline & $1975-76$ to $1979-80$ & 0.19 & 0.13 & 0.11 & 0.29 & 0.21 \\
\hline & $1980-81$ to $1982-83$ & 0.19 & 0.12 & 0.08 & 0.26 & 0.37 \\
\hline \multicolumn{7}{|c|}{ B. At Constant 1959-60 Prices } \\
\hline & $1960-61$ to $1964-65$ & 0.23 & 0.16 & 0.16 & 0.48 & 0.28 \\
\hline & $1965-66$ to $1969-70$ & 0.24 & 0.17 & 0.17 & 0.51 & 0.27 \\
\hline & $1970-71$ to $1974-75$ & 0.21 & 0.19 & 0.09 & 0.32 & 0.20 \\
\hline & $1975-76$ to $1979-80$ & 0.20 & 0.16 & 0.12 & 0.23 & 0.21 \\
\hline & $1980-81$ to $1982-83$ & 0.21 & 0.16 & 0.11 & 0.20 & 0.31 \\
\hline
\end{tabular}

Source: Calculations based on crop-production data in the Files of Planning Unit, Ministry of Food, Agriculture and Cooperatives.

It may not be without interest to note that the empirical results of this study, like an earlier study covering a limited post-Green Revolution period by one of the authors (Chaudhry 1982), are in sharp contrast with the conclusions of most of the studies undertaken during the late Sixties and early Seventies. The question, then arises, as to what went wrong with these studies. An attempt is made in the following subsection to answer this question.

\section{Factors in Regional Distribution of Income}

The trend of regional distribution of agricultural incomes is shaped by the relative pace of adoption of modern inputs and its implications for growth of pro ductivity of the various regions. The studies undertaken during the late Sixties and early Seventies involved a lot of speculation in the prediction of the distribution of benefits of the Green Revolution technologies. What is more important to note is the fact that this speculation was based on the regional pattern of adoption of various technologies in the early stages of the Green Revolution which ignored th more rapid adoption by the latecomers once the benefits of the technology were 
fully demonstrated [Hazell and Anderson (1984) and Pinstrup-Anderson and Hazell (1985)]. Given this state of affairs it may be important to analyse the regional pattern of adoption of the various Green Revolution technologies and changes therein with possible implications for the relative growth rates of agricultural production in the various provinces. The data in Table 3 are designed to accomplish this task.

The major conclusions follow from the examination of data in Table 3. First, Punjab played a leading role in the adoption of most of the Green Revolution technologies with the exception of HYVs of Rice and continued to maintain its dominant position over the period under consideration. The implication of this finding is that the Punjab enjoyed higher levels of agricultural productivity than other provinces. Second, what is more important from the standpoint of regional distribution of agricultural incomes is the change in the rates of adoption of various technologies in the provinces of Pakistan. It may be remarked that the incremental change in the adoption rates were more pronounced in other provinces than in the Punjab in the case of almost all the new technologies. On the basis of this finding it can be said that the faster rates of adoption of the Green Revolution technologies in Pakistan's provinces other than the Punjab were responsible for the rapid growth of agricultural output in Balochistan, NWFP and Sindh leading to a considerable narrowing of inter-provincial income disparities. Finally, the rapid rates of diffusion of Green Revolution technologies in all the provinces irrespective of their proportionate irrigated area point to the fact that the control on irrigation water has not been a binding constraint in the adoption of various technologies. In fact, the available evidence suggests that the access to water even in the non-irrigated areas of Pakistan may not be quite as precarious as has been portrayed by the studies undertaken during the late Sixties and early Seventies. For example, while the water requirements of most of the HYVs of wheat do not exceed 18 inches, the major Barani areas of Pakistan are endowed with more than 25 inches of annual rainfall (Muhammad 1970). The water constraints in the arid zones of Balochistan, NWFP and Sindh are considerably alleviated by the evolution of drought-resistant HYVs of wheat and the installation of tubewells. The introduction of tractors by promoting timely, quick and deep ploughing and levelling of fields greatly increases the water conservation potential of the rain-fed regions (Chaudhry 1986).

Although the population of tubewells and tractors is sparse in the arid zones, the two technologies have a far more significant effect on the agricultural productivity of such regions as compared to that of the irrigated areas. For example, since the productivity of agriculture in the rain-fed areas is only one-fourth of that in the irrigated regions, the installation of tubewells should lead to a three-fold increase in the income of the region (Johl 1979). This compares favourably with only a 100 percent increase in the incomes of irrigated regions with the installation of tubewells.
Table 3

Provincial Rates of Adoption of various Technologies in Pakistan for Selected Years

A. Tubewells (Number in $\mathbf{0 0 0}$ )

$1965-66$
$1970-71$
$1975-76$
$1980-81$
$1984-85$

$\begin{array}{lllll}34.3 & 1.3 & 0.5 & 0.6 & 93.5\end{array}$

$\begin{array}{lllll}89.5 & 4.1 & 1.7 & 1.9 & 92.1\end{array}$

$\begin{array}{lllll}144.2 & 8.4 & 3.7 & 4.7 & 89.6\end{array}$

$\begin{array}{lllll}172.1 & 15.4 & 5.0 & 7.2 & 86.2\end{array}$

1984-85

$\begin{array}{lllll}215.5 & 28.5 & 5.6 & 8.1 & 83.6\end{array}$

B. Fertilizer (000 Nutrient Tons)

1965-66

1970-71

$1975-76$

1980-81

1984-85

52.0

184.3

380.5

$697.7 \quad 303.3$

$824.4 \quad 342.5$

86.2

C. Tractors (Number in $\mathbf{0 0 0}$ )

$1970-71$
$1975-76$
$1980-81$
$1984-85$

1984-85

D. Dwarf Wheat Adoption Rate (Defined as Percentage of Total Wheat Area)

$1970-71$
$1975-76$
$1980-81$
$1984-85$

$\begin{array}{lllll}53.4 & 65.2 & 36.2 & 15.8 & 74.9 \\ 66.7 & 71.4 & 61.4 & 22.4 & 74.3 \\ 83.1 & 96.9 & 67.0 & 41.6 & 73.6\end{array}$

E. IRRI Rice Adoption Rate (Defined as Percentage of Total Rice Area)

$\begin{array}{rrrrrr}1970-71 & 13.4 & 63.1 & 5.3 & 61.6 & 18.0 \\ 1975-76 & 13.2 & 71.4 & 19.0 & 39.5 & 17.4 \\ 1980-81 & 18.7 & 78.5 & 18.2 & 75.6 & 23.7 \\ 1984-85 & 27.6 & 83.5 & 20.8 & 63.8 & 31.7\end{array}$

Source: Calculations based on data in [Government of Pakistan (1976) and (1986)] 
Similarly, it has been shown that a four-fold increase in wheat yields in arid zones, in contrast with the 10-20 percent increase in the irrigated areas, could be brought about with proper mechanization of tillage operations [Rana Tractors and Equipment Ltd. (1974)]. These results have largely been substantiated in recent years by the on-farm experiments under the Crop-maximization Programme of the Pakistan Agricultural Research Council which reiterate that the yields of wheat and maize in the Barani areas could be brought at par with those of the irrigated areas with deep ploughing and proper use of fertilizer (Chatta 1987).

In view of the rapid rates of diffusion of Green Revolution technologies and their significant contribution to agricultural production it is not difficult to see that the rain-fed regions were able to compete successfully with irrigated regions in agricultural productivity growth. It is substantiated by the trend in wheat (a crop grown under irrigated and unirrigated conditions) yields which have risen at a faster pace under Barani conditions than under irrigated agriculture throughout the Sixties, Seventies and the Eighties. In the recent years, research on evolution of HYVs of groundnut, oil seeds and blight-resistant gram varieties and Barani wheat and maize varieties have particularly been helpful in changing the outlook of agriculture in the poorer rain-fed regions of Pakistan [Pakistan Agriculture Research Council (1985)] . The outcome of these parallel developments has appeared in the form of substantial narrowing of the productivity gap between irrigated and unirrigated areas.

\section{CONCLUSIONS AND POLICY RECOMMENDATIONS}

The major purpose of this paper has been to study the trend of regional distribution of agricultural incomes in Pakistan. Taking gross value of crop output in the various districts from time to time, our empirical investigation points to a consistent improvement in the regional distribution of agricultural incomes in Pakistan. The conclusions of our study challenge the authority of arguments that anticipated widening income differences among the various regions. The studies undertaken during the late Sixties and early Seventies were based on the adoption rates of various technologies immediately after the inception of the Green Revolution and overplayed the constraint of irrigation water. Although Punjab with better irrigation facilities played the leadership role, the Green Revolution technologies were not restricted to Punjab alone and have been adopted by other provinces at a later stage. While the adoption rates seem to be a function of time to establish the profitability of the new inputs, water availability has not been a critical constraint in regional adoption patterns. In addition, our analysis shows that some of the Green Revolution technologies such as tubewells and tractors have a productivity-raising potential in the Barani areas that is considerably greater than that of the irrigated areas. Thus the Green Revolution represents an appropriate set of technologies suited to all regions and perhaps more so to poorer regions. It is, therefore, in the best interest of Pakistan to propagate, by deliberate policy action, the use of existing technologies in all regions and to undertake research on the evolution of new ones with renewed vigour.

\section{REFERENCES}

Alavi, Hamza (1976). "The Rural Elite and Rural Development in Pakistan". In Robert D. Stevens et al. (eds.), Rural Development in Bangladesh and Pakistan. Honolulu: The University Press of Hawaii.

Chaudhry, M. Ghaffar (1982). "Green Revolution and Redistribution of Rural Incomes: Pakistan's Experience”. Pakistan Development Review. Vol. XXI, No. 3.

Chaudhry, M. Ghaffar (1986). "Mechanization and Agricultural Development in Pakistan". Pakistan Development Review. Vol. XXV, No. 4.

Chatta, Muhammad Qasim (1987). "Improving Rice, Maize and Wheat Production Through CMP Approach". The Muslim, A Supplement. (Tuesday December, 15)

Falcon, W. P. (1970). "The Green Revolution; Second Generation Problems". American Journal of Agricultural Economics. Vol. 52.

Gotsch, Carl H. (1973). "Tractor Mechanization and Rural Development in Pakistan". International Labour Review. Vol. 107.

Gotsch, Carl H. (1976). "Relationship Between Technology, Prices and Income Distribution in Pakistan's Agriculture: Some Observations on the Green Revolution". In Robert D. Stevens et al. (eds.), Rural Development in Bangladesh and Pakistan. Honoululu: The University Press of Hawaii.

Gotsch, Carl H. (1976a). "The Green Revolution and Future Development of Pakistan's Agriculture”. In Robert D. Stevens et al. (eds.), Rural Development in Bangladesh and Pakistan. Honolulu: The University Press of Hawaii.

Griffin, Keith (1974). "The Political Economy of Agrarian Change". Cambridge, Mass. (USA): Harvard University Press.

Hamid, Naved, and Akmal Hussain (1974). "Regional Inequalities and Capitalist Development". Pakistan Economic and Social Review. Vol. 12, No. 4.

Hazell, Peter B. R., and Jock R. Anderson (1984). "Public Policy Toward Technical Change in Agriculture". Greec Economic Review. Vol. 6, No. 3.

Johl, S. S. (1979). "Mechanization, Labour Use and Productivity in Agriculture" Agricultural Studies in India. Vol. 28, No. 1.

Muhammad, Ghulam (1970). "Private Tubewell Development and Cropping Patterns in West Pakistan". Reading in Development Economics. Karachi: Pakistan Institute of Development Economics. (Reading No. 3).

Pakistan, Government of (1976). Agricultural Statistics of Pakistan 1975. Islamabad: Ministry of Food, Agriculture and Co-operatives (Planning Unit). Vol. 1.

Pakistan, Government of (1985). Annual Report 1984-85: Barani Agricultural Research and Development Project. Islamabad: Pakistan Agricultural Research Council. 
Pakistan, Government of (1986). Agricultural Statistics of Pakistan 1985. Islamabad: Ministry of Food, Agriculture and Co-operatives (Planning Unit).

Pinstrup-Anderson, P., and Peter B. R. Hazell (1985). "The Impact of the Green Revolution and Prospects for the Future". Food Reviews International. Vol. 1.

Rana Tractors and Equipment Ltd. (1974). "Dry Land Farming Project in Pakistan". Islamabad. (Mimeographed)

\section{Comments on}

\section{"Regional Distribution of Agricultural Incomes in}

Pakistan: Intertemporal Analysis"

It is a well-known fact that the new technology and the environment (in which it is adopted) adapt to each other; the question is only of time that would elapse in this adaption. Intuitively, it is also clear that with the diffusion of technology income inequalities between the initial and later adopters will be reduced. There are, however, a few methodological questions which bother the reader:

(1) Gross Value Product (GVP) is at best a mere proxy for agricultural income as it ignores the cost of inputs. As different regions may be using a different input mix for production of the same crop and paying differen prices for the same inputs this would result in a different net income per unit of output. One cannot blame the authors for not calculating the ne incomes as one realizes the enormity of the task given the data situation in the country.

(2) One may question the utility of calculating 5-year averages for shares of agricultural incomes (Table 1). Not only that a lot of information gets los in these averages but also it makes the comparison of these shares with the shares of various components of agricultural technology (Table 3) very difficult. One feels that provision of income shares for the years corresponding to those given in Table 3 or alternatively, calculation of 5-year averages for the components of technology would have been more helpful to determine the correlation between income shares and the provincial share of a particular component of new technology

(3) Table 2 provides the Income Concentration Ratios (ICRs) for the country as well as for the four provinces. These ICRs are calculated as substitutes for income shares which, as the authors point out, are not appropriate measures of income inequality. However, the presentation of ICRs mark a sudden switch in the emphasis of the paper from inter-provincial to intra-provincial (i.e., inter-district) inequalities. As no supporting information about the inter-district diffusion of new technology is provided on cannot understand the usefulness of Table 2 .

(4) Two crucial factors conspicuous by their absence from the paper are the 'area cultivated' and 'area irrigated'. The paper completely ignores that the changes in provincial shares of these variables could be a possible reason for reduction in inter-provincial inequalities. 


\section{Incorporation of Points (2) and (4)}

In order to incorporate points (2) and (4) related to consistency of data series and the inclusion of cultivated and irrigated areas, data on area cultivated, area irrigated (by all sources), number of tubewells, amount of fertilizer used, area under high-yielding varieties of wheat and rice were obtained from various issues of Agricultural Statistics of Pakistan. Five-year averages of these variables are given in Table 1.' These averages were used to calculate simple correlation coefficients (not reported) between income shares and the shares of various components of technology. These coefficients reveal that, except for Balochistan, the correlation between income shares and shares of components of technology is mostly negative.

Table 1

Provincial Shares in Income and various Factors (Averages)

\begin{tabular}{ccccc}
\hline Years & Punjab & Sindh & NWFP & Balochistan \\
\hline \multicolumn{2}{l}{ Income (in Current Prices) } & & & \\
\multicolumn{1}{c}{$1961-1965$} & 64.7000 & 24.1000 & 8.80000 & 2.50000 \\
$1966-1970$ & 63.0000 & 25.4000 & 9.00000 & 2.60000 \\
$1971-1975$ & 64.3000 & 24.2000 & 9.00000 & 2.50000 \\
$1976-1980$ & 60.9000 & 25.7000 & 9.90000 & 3.50000 \\
$1981-1983$ & 59.3000 & 25.6000 & 9.70000 & 5.40000 \\
Income (in Constant Prices) & & & \\
$1961-1965$ & 63.7000 & 24.3000 & 9.40000 & 2.60000 \\
$1966-1970$ & 60.2000 & 26.5000 & 10.2000 & 3.10000 \\
$1971-1975$ & 61.2000 & 25.9000 & 9.60000 & 3.40000 \\
$1976-1980$ & 60.2000 & 26.5000 & 9.60000 & 3.60000 \\
$1981-1983$ & 60.2000 & 25.8000 & 9.40000 & 4.60000 \\
Cultivated Area & & & & \\
$1961-1965$ & 55.5700 & 27.1900 & 6.95000 & 10.2900 \\
$1966-1970$ & 56.2700 & 27.3600 & 7.57000 & 8.80000 \\
$1971-1975$ & 57.6600 & 27.4500 & 8.70000 & 6.19000 \\
$1976-1980$ & 56.7000 & 27.2100 & 9.46000 & 6.62000 \\
$1981-1983$ & 56.6500 & 27.0300 & 9.28000 & 7.04000 \\
\hline
\end{tabular}

'As data for fertilizer were available form 1966, therefore, average for 1961-65 could not be calculated. Data for tubewells and area on high yielding varieties were available from 1969 , hence the first average for these variable is calculated for two years only. Appropriate data on number of tractors in each province were not available.
Table $1-($ Continued $)$
$1961-1965$

1966-1970

1971-1975

$1976-1980$

1981-1983

65.7800

66.9700

69.6700

69.0300

70.8500

\section{Irrigated Area}

27.7000

24.9300

21.7100

22.6500

20.4900
4.82000

4.80000

5.16000

4.91000

5.02000
2.19000

3.30000

3.16000

3.42000

3.64000

\section{Tubewells}

$\begin{array}{ccccc}1961-1965 & \text { NA } & \text { NA } & \text { NA } & \text { NA } \\ 1966-1970 & 94.8600 & 2.74000 & .370000 & 2.04000 \\ 1971-1975 & 90.9400 & 4.73000 & 1.73000 & 2.60000 \\ 1976-1980 & 88.8000 & 5.64000 & 2.39000 & 3.16000 \\ 1981-1983 & 84.6400 & 9.46000 & 2.49000 & 3.59000\end{array}$

\section{Fertilizer}

$\begin{array}{ccccl}1961-1965 & \text { NA } & \text { NA } & \text { NA } & \text { NA } \\ 1966-1970 & 70.8800 & 19.5000 & 9.43000 & .190000 \\ 1971-1975 & 65.6800 & 27.1400 & 6.85000 & .320000 \\ 1976-1980 & 66.6900 & 25.5900 & 7.29000 & .430000 \\ 1981-1983 & 65.4000 & 27.4000 & 6.65000 & .550000\end{array}$

Area Under High Yielding Variety (Wheat)

$\begin{array}{ccccc}1961-1965 & \text { NA } & \text { NA } & \text { NA } & \text { NA } \\ 1966-1970 & 79.7700 & 14.1500 & 5.01000 & 1.07000 \\ 1971-1975 & 74.5300 & 16.3700 & 8.47000 & .620000 \\ 1976-1980 & 73.7700 & 15.9300 & 9.39000 & .910000 \\ 1981-1983 & 73.1900 & 16.1400 & 9.83000 & 1.83000\end{array}$

Area Under High Yielding Variety (Rice)

$\begin{array}{ccccc}1961-1965 & \text { NA } & \text { NA } & \text { NA } & \text { NA } \\ 1966-1970 & 21.8000 & 77.3800 & .700000 & .120000 \\ 1971-1975 & 20.1500 & 74.8300 & 1.17000 & 3.84000 \\ 1976-1980 & 28.3600 & 68.2700 & 1.33000 & 2.04000 \\ 1981-1983 & 22.0800 & 67.6400 & 1.60000 & 8.68000\end{array}$

